\title{
Egzzulcerated form of adrena!
}

\section{incidentaloma and hemodynamic state of patient}

Djurdjevic Svraka A. ${ }^{1}$, Svraka D. ${ }^{2}$, Golic D. ${ }^{2}$, Rakanovic D. ${ }^{2}$

${ }^{1}$ General Hospital Gradiska, Dept of Anaesthesiology \& Intensive Care, Gradiska, Bosnia and Herzegovina, ${ }^{2}$ University Hospital Clinical Center, Dept of Anaesthesiology \& Intensive Care, Banja Luka, Bosnia and Herzegovina

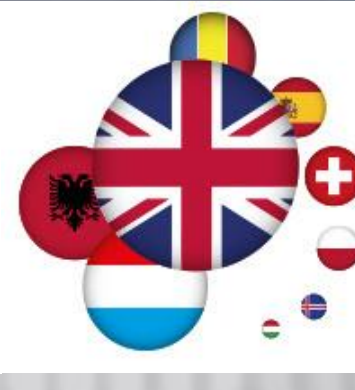

LONDON, UK

Euroanaesthesia The European Anaesthesiology Congres

Pheochromocytomas and paragangliomas (PHEO/PGL) are chromaffin cell tumors that embryonically derive from the neural crest and functionally are capable of production, storage, metabolism, and secretion of catecholamines.About 4-10\% of PHEOs are found as adrenal incidentaloma, whereas approximately $5 \%$ are diagnosed at surgery. (1)

58 year old patient was admitted to the clinic for abdominal surgery with signs of acute abdomen, intermittent unrensponsiveness, abdominal pain and hypertension.

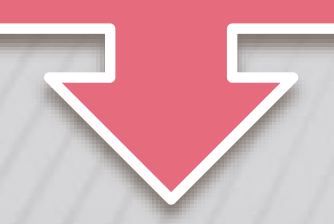

At the addmitance the lab. came : hematocrit 0,52, Hgb 142, abdominal ultrasound detected presence of intraabdominal fluid and meteorism, abdominal computed tomography detected unspecific changes of the right adrenal gland. Surgeon called for immediate exploratory laparatomy.

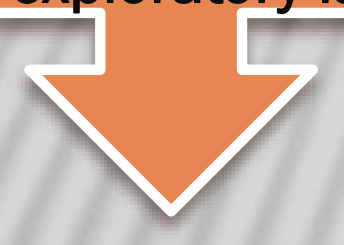

Upon entering the operating room patient collapses, Sp02 96\% HR 130/min; TA 245/120 mmHg. After induction of general endotracheal anesthesia central venous catheter (v.jugularis interna) and catheter for invasive measurement of arterial pressure (a.radialis) were placed.
Surgical exploration find exulceration tumor of right adrenal glandsuspicion of pheochromocytoma. Arterial pressure intraoperatively controlled with Urapidil continuous infusion. Before clamping adrenal

drainage veins we decreased Sevofluran concentration and discontinued Urapidil infusion all together. Total intraoperative blood loss was $850 \mathrm{ml}$, two units of packed RBCs and two units of FFP were administred.

After tumor removed the patient entered a hemodynamic stabile state. Postoperativly patient was awake, aware, hemodynamically and respiratory compensated and placed in ICU at Clinic for anesthesiology and ICU. In consultation with endocrinologist offices endocrinological diagnostics (norepinephrine $705 \mathrm{mcg}$; epinephrine108mcg; dopamine $387 \mathrm{mcg}$; VMA $12,3 \mathrm{mcg}$ u $24 \mathrm{~h}$ urine).

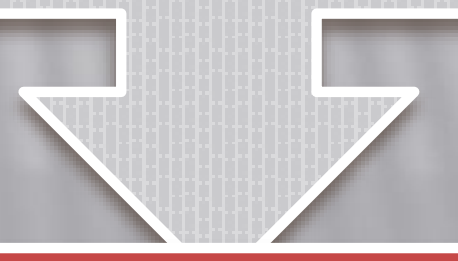

Histopathology confirmed pheochromocytoma.

Discussion: Mortality during anesthesia in previosly undiagnosed pheochromocytoma patient that was subjected to non-related surgery or surgical procedure is up $50 \%$. (2) Learning point: The anesthetist should think of incidentaloma in patient with hypertensive crisis, especially because providing hemodynamically stable state is very challenging.

\section{References:}

(1) De Groot LJ, et all;SourceEndotext [Internet]. South Dartmouth (MA): MDText.com, Inc.; $2000-.2015$ Apr 12.

(2) Owen R. Anesthetic Consideration in Endocrine Surgery, "Surgical Endocrinology",19 93.Ch7,P71-84 